\title{
2006: LA ELECCIÓN INCIERTA
}

José Antonio Crespo*

\section{Introducción}

La elección presidencial de 2006 supone algo inédito en la historia política de México, como casi todo lo que sucede en un período de transición política en el que el país se halla inmerso desde hace varios años (en México, y a diferencia de otros países, es difícil marcar el inicio formal de dicho proceso). Es, en todo caso, la primera elección en décadas organizada bajo un gobierno distinto al PRI, lo que teóricamente hubiera representado un avance en términos de pulcritud, imparcialidad, equidad y credibilidad, en virtud también de que el partido en el gobierno, el PAN, fue durante seis décadas el principal referente político en defensa de la democracia política y el respeto al voto. No fue así, o por lo menos, cerca de la mitad de la ciudadanía no lo vio de esa manera, lo que en sí mismo refleja que se perdió el consenso que se había obtenido en el año 2000 (ver Gráfica 1).

El consenso electoral no supone que una abrumadora mayoría vote por el mismo candidato (como no ocurrió tampoco en 2000), sino que esa mayoría acepte que, quien ganó oficialmente, lo hizo en buena lid y en condiciones suficientemente democráticas como para no regatearle un ápice de su legitimidad político-electoral. Eso sí se logró en el año 2000 , cuando Vicente Fox, con el $43 \%$ de la votación, fue reconocido por tirios y troyanos. Debe recordarse, en todo caso, que en 2000 se

\footnotetext{
* Profesor-Investigador de la División de Estudios Políticos, CIDE.
} 
dio la primera alternancia pacífica del poder en la historia de México. Antes de eso, el traspaso del poder de un grupo político a otro distinto se había dado por medio de la violencia: un golpe de Estado, una revolución o una guerra civil. Jamás de manera pacífica y civilizada por la vía electoral, hasta el año 2000. Eso fue tomado no como el inicio de la transición democrática (que viene de más atrás), sino como uno de los resultados más palpables de dicho proceso y como un valioso precedente para profundizar la democratización en el país.

\section{GRÁFICA 1}

¿Usted cree o no que hubo fraude en las pasadas elecciones presidenciales?

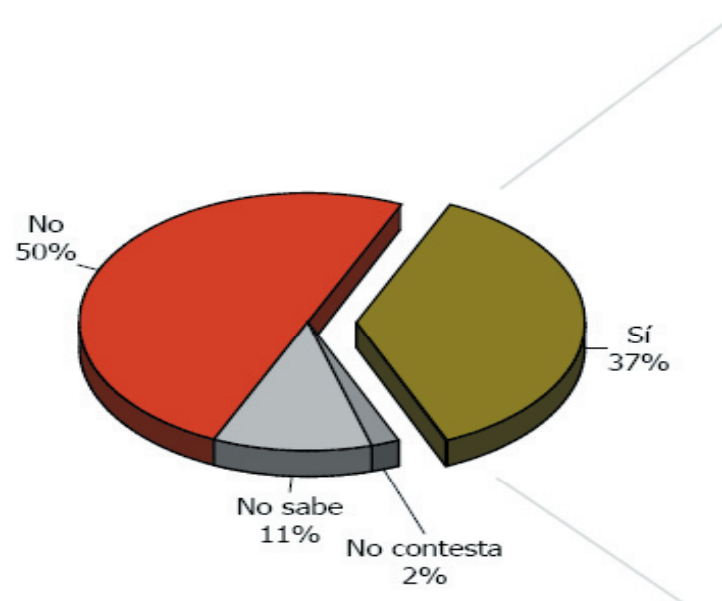

FUENTE: IFE-Parametría, septiembre 2006.

Debe considerarse, también, que el 2000 fue la primera vez en mucho tiempo que el final del sexenio no fue conflictivo, ni política ni económicamente, lo que puede encontrar su explicación en las medidas que en uno y otro ámbito tomó el presidente Ernesto Zedillo. Pero eso también se perdió, en buena medida, en 2006, pues si bien no hubo una crisis económica, sí la hubo nuevamente en el ámbito político, 
con un conflicto pos-electoral marcado por una fuerte polarización social (es decir, la división de buena parte de la sociedad en dos bloques principales, en torno a un asunto político y con gran rijosidad y vehemencia de por medio). Así, el sano precedente democrático del año 2000 se desdibujó, pues la consolidación democrática (es decir, el fortalecimiento y resistencia de los acuerdos y procesos democráticos) requiere de varios precedentes exitosos. La interrupción de esa serie (en este caso, de elecciones incuestionables) dificulta esa consolidación e incluso puede dar paso a lo que se conoce como 'regresión política', es decir, el retorno a prácticas e instituciones no democráticas que son justamente las que se pretende modificar con la democratización. ${ }^{1}$ Para comprender a cabalidad lo que puede significar la elección presidencial del 2006, conviene enmarcarla en un contexto más amplio, tanto histórico como institucional, más allá de sus peculiaridades y pormenores específicos.

\section{Crisis cíclicas de fin de sexenio}

Al menos desde 1976, el país sufrió una crisis de fin de sexenio, aunque con distinta intensidad y por diferentes motivos. En ese año, lo mismo que en 1982, las crisis tuvieron esencialmente un origen económico, pero que golpearon fuertemente la legitimidad del régimen priísta, debilitándolo significativamente. Eso mismo creó las condiciones para que el tradicional control político de corte autoritario se empezara a dificultar. En 1988 hubo también una crisis de fin de sexenio, igualmente con tintes económicos pero fundamentalmente de origen político, enmarcada por una ruptura grave del PRI en 1987, y la consecuente candidatura de Cuauhtémoc Cárdenas, por quien votaron numerosos segmentos del régimen, descontentos con el nuevo modelo económico adoptado por Miguel de la Madrid, llamado genéricamente 'neolibe-

${ }^{1}$ Cfr. Samuel Huntington, The Third Wave: Democratization in the Late Twentieth Century, 1991, University of Oklahoma Press, Norman. 
ralismo', que implicó una política de austeridad y la reducción de los privilegios económicos para los líderes de los sectores corporativos del PRI, andamiaje esencial del régimen posrevolucionario. ${ }^{2}$ Varios de ellos, o sus agremiados, sin abandonar el PRI sufragaron por Cárdenas, dándole un caudal de votos que pudo haberlo hecho ganar la elección (lo cual quedó incierto) y que orilló al gobierno en turno a cometer un monumental fraude electoral, hoy reconocido por todos (aunque en ese año muchos sostuvieron que no hubo tal fraude o, si acaso, que no fue tan grande como para poner en duda la legitimidad del triunfo del candidato oficial, Carlos Salinas de Gortari). Contó también el fortalecimiento del PAN, sobre todo a raíz de la crisis de 1982, que generó descontento en amplios sectores de la clase media, que orientaron su voto y respaldo hacia el blanquiazul, así como la llegada a ese partido de importantes empresarios, molestos con la estatización de la banca que arbitrariamente decidió José López Portillo, durante su último informe presidencial (1982). ${ }^{3}$ Las dos oposiciones ya fortalecidas, el PAN y la encabezada por Cárdenas (quien fue postulado por un amplio frente de partidos de izquierda), generaron la crisis electoral de ese año, con un conflicto que puso en riesgo la estabilidad social, si bien Cárdenas decidió no convocar a sus partidarios a la confrontación y apostó por cristalizar su movimiento en un nuevo partido político, el de la Revolución Democrática (PRD).

El gobierno de Salinas de Gortari terminó también en una crisis política, que desencadenó otra de tipo económico, sumamente severa. La aparición pública de la guerrilla chiapaneca a principios de ese año afectó el proceso electoral y desató una dinámica política en medio de la cual se dio el asesinato del candidato oficial, Luis Donaldo Colosio (sustituido por Ernesto Zedillo), y poco después del secretario general del PRI, José Francisco Ruiz Massieu. Las salidas de capital durante

${ }^{2}$ Cfr. Luis Javier Garrido, La ruptura: la Corriente Democrática del PRI, 1993, México, Grijalbo.

${ }^{3}$ Cfr. Soledad Loaeza, El Partido Acción Nacional: la larga marcha, 1939-1994, 1999, México, FCE. 
ese año redujeron al límite las reservas internacionales lo cual, aunado a un mal manejo de una inevitable devaluación monetaria, provocó una crisis económica más grave aún que la de $1982 .{ }^{4}$

Frente a todos esos antecedentes, el presidente Zedillo comprendió que no había ya condiciones para prolongar la tradicional hegemonía del PRI, por lo que aceptó una amplia apertura política, dio un paso decisivo a un sistema electoral cabalmente competitivo. Eso, y la marcada tendencia a la baja de la votación del PRI provocaron, primero, la pérdida de la mayoría absoluta de ese partido sobre la cámara baja del Congreso y del gobierno de la capital (en 1997), y, tres años después, de la presidencia de la República. Zedillo comprendió que la viabilidad del modelo económico vigente de su preferencia se pondría en riesgo de no abrir de par en par el sistema electoral y partidista, pues ello supondría tensar nuevamente la cuerda de la estabilidad política. Prefirió exponer el poder de su partido (por lo cual ha sido considerado como un traidor por sus correligionarios) que arriesgar la estabilidad del país. ${ }^{5}$ La alternancia consecuente, a favor del PAN, abrió una enorme oportunidad para consolidar la democracia electoral y profundizar ese régimen en otros ámbitos (como el indispensable de la rendición de cuentas, sin lo cual no puede hablarse de un ejercicio y control democráticos del poder). Y también representó la primera vez en mucho tiempo de un fin de sexenio sin crisis política ni económica, precedente que debió ser repetido para fortalecer la frágil y no garantizada democratización del país. Sin embargo, el primer gobierno emanado de la oposición, por diversas razones, no favoreció esa tendencia, y en cambio generó condiciones que dieron lugar a una nueva crisis de fin de sexenio, esta vez exclusivamente político-electoral. ${ }^{6}$ Una crisis que podría tener perjudiciales secuelas políticas y

\footnotetext{
${ }^{4}$ Cfr. José Antonio Crespo, Urnas de Pandora: partidos y elecciones en el gobierno de Salinas, 1995, México, Espasa-Calpe.

${ }^{5}$ Cfr. Cfr. José Antonio Crespo, ¿Tiene futuro el PRI? Entre la supervivencia y la desintegración total, 1998, México, Grijalbo.

${ }^{6} \mathrm{Cfr}$. Alejandra Lajous, Vicente Fox. El presidente que no supo gobernar, 2007, México, Océano.
} 
sociales, dado el rijoso clima de polarización que precedió la elección presidencial y que se intensificó una vez celebrada ésta.

\section{La estrategia frente a las oposiciones: cerrazón o apertura}

Para entender estas crisis cíclicas hay una variable (entre muchas) de tipo político que resulta clave: la estrategia hacia las oposiciones, ubicadas a la derecha e izquierda del PRI. El punto de partida es un principio general de la política democrática (o semi-democrática); cuando se abren los canales institucionales a la oposición y la disidencia, éstas tienden a moderarse (que no es lo mismo que claudicar a su causa); si en cambio se cierran u obstruyen dichos canales, la oposición y la disidencia tienden a radicalizarse. Y la radicalización de las oposiciones en pleno traspaso del poder gubernamental, incrementa la probabilidad de que se genere una crisis política, que puede afectar o no la economía (según las condiciones vigentes en cada ocasión). Eso, considerando además que en todo régimen político ( $\sin$ importar el momento histórico ni la latitud regional), la sucesión del poder genera riesgos y tensiones que pueden amenazar la estabilidad política. Y es que la pugna por el poder moviliza a diversos grupos sociales, económicos y políticos que desean ocupar directamente el poder o influir decisivamente sobre quién recaerá éste. Lo que está en juego es mucho, por lo cual, si las reglas para dirimir esta sucesión no están sólidamente fortalecidas ( no esencialmente democráticas o autoritarias), entonces la sucesión política se vuelve sumamente conflictiva e incluso conlleva el riesgo de desatar las hostilidades entre los contendientes y sus partidarios. Mal manejada la sucesión, podría dar lugar a disturbios, un golpe de Estado, una revolución o una guerra civil. ${ }^{7}$ Ejemplos de ello sobran, lo mismo en la historia universal que en la de México.

${ }^{7}$ Cfr. Samuel Huntington, El orden político en las sociedades en cambio, 1972, Buenos Aires, Paidós. 
Las crisis políticas de fin de sexenio deben también enmarcarse en el agotamiento gradual de la institucionalidad política del régimen priísta, que había logrado resolver perfectamente el problema de la sucesión del poder sexenalmente, aunque por medio de reglas claramente autoritarias. Cuando dichas reglas se fueron agotando (lo mismo dentro del PRI como en relación a la oposición), los riesgos de conflictividad durante cada sucesión del poder gubernamental tendieron a incrementarse. Por eso hubo graves crisis políticas en las sucesiones posteriores a la revolución (1920, 1923, 1928, 1929), y en la etapa final del régimen priísta (1988 y 1994). Al principio se debió a la fragilidad de la nueva institucionalidad (reglas y procedimientos), $\mathrm{y}$ al final, por su agotamiento. ${ }^{8}$

Volviendo a la forma en que los distintos gobiernos enfrentaron la oposición partidista, según el cual la apertura genera moderación y la cerrazón radicalismo, hagamos un breve repaso de cómo se manejó esto en los últimos años, ya en el ámbito de la transición política. José López Portillo (1976-1982) experimentó el agotamiento del régimen de partidos y de la legitimidad política del régimen, que se tradujo en que fue el único candidato que contendió por la presidencia (lo que desproveía al régimen de sus atuendos democráticos, exponiéndolo como partido prácticamente único), por lo cual instrumentó en 1979 una reforma política (aunque no plenamente democrática) que ofreció mejores condiciones de competencia a la oposición, incorporando a grupos y partidos de la izquierda histórica (marxista y revolucionaria) hasta entonces excluidos del sistema de partidos. ${ }^{9}$ Es decir, aplicó una estrategia de apertura hacia las oposiciones de derecha e izquierda, que se tradujo en moderación, revigorizando además el sistema de partidos y arrojando una nueva bocanada de legitimidad sobre el régimen. Por lo cual, en 1982 no hubo conflictividad político-electoral, sino incluso

${ }^{8}$ Cfr. José Antonio Crespo, Los riesgos de la sucesión presidencial. Actores e instituciones rumbo al 2000, 1999, México, Centro de Estudios de Política Comparada.

${ }^{9}$ Cfr. Octavio Rodríguez Araujo, La reforma política y los partidos en México, 1979, México, Siglo XXI. 
gran pluralidad con varios candidatos en contienda. ${ }^{10}$ La crisis, ese año, respondió a variables fundamentalmente económicas.

El sucesor de López Portillo, Miguel de la Madrid (1982-1988), echó reversa a la apertura política, pese a haberla ofrecido como compensación a la austeridad económica, por el temor que le suscitó el fortalecimiento de la oposición. El PAN ganó presencia y alcaldías importantes sobre todo en el norte del país (Ciudad Juárez, Chihuahua, San Luis Potosí, Durango), lo que impulsó a De la Madrid a detener ese avance por medio del tradicional recurso al fraude electoral (claramente en Durango y Chihuahua, en 1986). ${ }^{11}$ Lo anterior se tradujo en una postura radicalizada de los panistas, que en 1988 postularon como candidato presidencial a un líder carismático y temerario, salido de las filas empresariales: Manuel Clouthier. Por el lado de la izquierda, desde su incorporación a la lucha electoral en 1979, se había moderado ideológica y estratégicamente (abandonando la retórica marxista, la hoz y el martillo, la internacional socialista), pero no sumaba más del 5\% de la votación. ${ }^{12}$ No representaba un desafío real al régimen. Sin embargo, la inconformidad dentro del PRI tradicional (nacionalista-revolucionario), consecuencia de las políticas neoliberales de 82 De la Madrid, generó una grave ruptura en el partido hegemónico (la última había tenido lugar en 1952, que terminó por ser reparada), permitiendo aglutinar a la izquierda histórica en torno de la candidatura de Cuauhtémoc Cárdenas, quien también captó el respaldo de segmentos priístas afectados por el neoliberalismo. La reacción del gobierno ante la disidencia dentro del PRI (la Corriente Democrática), fue de cerrazón, lo que precipitó la ruptura y radicalización de ese movimiento. ${ }^{13}$ Por ello, la elección presidencial de 1988 enfrentó dos movimientos opositores fuertes y radicales, lo que orilló al régimen

${ }^{10} \mathrm{Cfr}$. Juan Molinar, El tiempo de la legitimidad: elecciones, autoritarismo y democracia en México, 1991, México, Cal y Arena.

${ }^{11}$ Cfr. Juan Molinar, "Regreso a Chihuahua", en Nexos, n 111, marzo de 1987.

${ }^{12}$ Cfr. Arturo Anguiano, Entre el pasado y el futuro. La izquierda en México, 1969-1995, 1997, México, UNAM.

${ }^{13}$ Cfr. Garrido, La ruptura..., op. cit. 
a recurrir a un magno fraude electoral, con el consecuente conflicto político. En otras palabras, De la Madrid, por temor al crecimiento de la oposición, practicó la política opuesta de López Portillo: en lugar de apertura, cerrazón. Y obtuvo los efectos contrarios a los de la apertura lópez-portillista; en lugar de moderación y tranquilidad en la sucesión presidencial, se generó radicalismo y conflictividad. ${ }^{14}$

Carlos Salinas de Gortari (1988-1994) entendió parcialmente las lecciones de 1988. Por un lado, entabló una alianza integral con el PAN, cuyo programa económico era compatible con el neoliberalismo abanderado por De la Madrid y fortalecido por el propio Salinas, a cambio de lo cual se reconocerían algunos de los triunfos incontestables del PAN a nivel regional (contrariamente a lo ocurrido en 1986), por lo que se reconocieron victorias panistas a nivel de gubernatura en Baja California (1989), Guanajuato (1991) y Chihuahua (1992), así como varias plazas municipales de importancia. El resultado de dicha apertura fue la moderación del panismo (no sólo a nivel del partido, sino de individuos, como Francisco Barrio, cuyo radicalismo como candidato por Chihuahua en 1986 se transformó en una postura moderada, incluso rayana en colaboración con el gobierno de Salinas, 1o cual le permitió, ahora sí, ser gobernador de su entidad en 1992); de este modo, por el flanco derecho, Salinas siguió una estrategia similar a la de López Portillo, con efectos estabilizadores.

Sin embargo, dicha apertura fue parcial (selectiva, se le llamó), pues no se aplicó en el caso de la pujante izquierda. Salinas, además de sentirse agraviado dado que su triunfo fue escatimado y opacado por Cárdenas, temió el potencial político-electoral del PRD, por lo que su reacción fue de hostigamiento y cerrazón. Le aplicó el tradicional fraude, arrebatando una posible victoria del PRD, al menos en el Congreso de Michoacán (origen regional del neocardenismo) en 1989, y poco después en esa misma entidad, en la contienda por la gubernatura (1992). Puede decirse que en 1992 Michoacán tuvo efectos

${ }^{14}$ Cfr. Pablo González Casanova (coord.), Segundo Informe sobre la democracia en México: el 6 de julio de 1988, 1990, México, Siglo XXI. 
similares en el PRD que los de Chihuahua y Durango en 1986 en el PAN. El resultado fue una mayor radicalización del PRD y de algunos grupos sociales identificados con él. Si bien dicha estrategia se tradujo en el debilitamiento electoral del PRD, por eso mismo intensificó la movilización de los grupos de izquierda extra-institucionales. Uno de ellos fue el Ejército Zapatista de Liberación Nacional (EZLN), quien, al irrumpir en 1994, justificó su recurso a las armas a partir de que, por el lado de la izquierda, se habían cerrado los canales institucionales a diferencia de lo ocurrido respecto de la derecha, lo cual era exacto. Su discurso democrático en parte le permitió gozar del respaldo e incluso legitimidad entre buena parte de la población, complicando enormemente la elección de ese año, según se vio. En otras palabras, la apertura de Salinas hacia el PAN se tradujo en la moderación de éste, pero la cerrazón hacia el PRD se tradujo en la radicalización de la izquierda (incluido el EZLN), lo que le complicó la sucesión presidencial, traducida en una nueva crisis política y económica. ${ }^{15}$

Ernesto Zedillo entendió cabalmente la lección de 1994 y decidió que, para conjurar el ciclo de crisis de fin de sexenio, era menester abrir los canales institucionales, no sólo al PAN como había hecho Salinas,

84 sino también al PRD. ${ }^{16}$ Aceptó la plena autonomía y nuevas facultades a las autoridades electorales, el Instituto Federal Electoral (IFE) y el Tribunal Electoral del Poder Judicial de la Federación (TEPJF). También impulsó una nueva ley electoral plenamente competitiva (1996) y se dispuso a aceptar todo triunfo que legítimamente ganara la oposición, lo mismo a la derecha que a la izquierda del PRI. ${ }^{17}$ El PAN continuó ganando nuevas plazas, como la de Jalisco, Querétaro y Nuevo León. Al PRD le fue reconocida una importante victoria en el gobierno de la capital (1997), y más tarde en Zacatecas (producto de una nueva ruptura dentro del PRI). Esto se tradujo en la moderación política no sólo del

${ }^{15}$ Cfr. Crespo, Urnas de Pandora..., op. cit.

${ }^{16}$ Cfr. José Antonio Crespo, Jaque al rey: hacia un nuevo presidencialismo en México, 1996, México, Joaquín Mortiz.

${ }^{17}$ Cfr. José Woldenberg, Ricardo Becerra y Pedro Salazar, La reforma electoral de 1996: una descripción general, 1997, México, FCE. 
PAN, sino también del PRD (con la consecuente pérdida de influencia de los movimientos extremistas de ese polo del espectro ideológico, incluido el EZLN). Lo anterior preparó políticamente el terreno para una sucesión presidencial ordenada y civilizada que, además (y por razones ya mencionadas), se tradujo en la primera alternancia pacífica del poder (que favoreció al candidato del PAN, Vicente Fox). Desde luego, tampoco hubo una crisis económica sino que el país registró en ese año un inusual crecimiento económico del 7\%. La ya tradicional crisis de fin de sexenio fue evitada, al menos por esta ocasión, pero no por casualidad, sino porque Zedillo tomó con tiempo y racionalidad las medidas adecuadas para alcanzar ese importante objetivo.

\section{La opción estratégica de Fox}

Vicente Fox llegó con la mayor legitimidad democrática y electoral registrada en la historia (ni siquiera Benito Juárez o Francisco Madero gozaron de esa situación). Pero no continuó con la política de apertura democrática iniciada por su antecesor, sino que, por diversas razones (y probablemente de forma inconsciente), aplicó a la oposición la estrategia seguida por Salinas de Gortari: apertura a una parte de ella (el PRI, en este caso, a quien se le extendió una carta de impunidad), y creciente cerrazón y hostigamiento a otra parte de la oposición (el PRD, nuevamente). Las razones de ello no están del todo claras y pueden haber sido diversas: A) el riesgo de que un eventual ascenso al poder del PRD trastocara la política neoliberal (que también Fox siguió); B) una rivalidad personal entre el precandidato más fuerte de ese partido y jefe de gobierno de la capital, Andrés Manuel López Obrador; C) la intención de despejar el camino a la presidencia a su esposa, Marta Sahagún, quien abrigaba tales pretensiones; o, D) el temor de que López Obrador, no muy proclive a la negociación pragmática con sus rivales, desde la presidencia llamara a cuentas a Fox y su esposa por presuntos actos de corrupción e ilícito enriquecimiento familiar. Cualquiera de estas razones, o todas en combinación, podrían explicar 
la decisión de Fox para poner trabas en el camino de López Obrador a Los Pinos, quien casi desde el principio empezó a encabezar las encuestas de preferencia electoral. La relación entre ambos personajes fue de civilidad y respeto durante los primeros años, aunque con algún intercambio de declaraciones incómodas, pero que no salían de la normalidad política (incluyendo la que rige en las democracias).

A fines de 2003 se registró ya un suceso que auguraba posibles dificultades para a elección de 2006: el Instituto Federal Electoral (IFE), que había cobrado en sus últimos años gran prestigio y credibilidad, perdió el consenso partidista que le había dado fuerza y funcionalidad tanto en 1994 como en 1996 (fechas en que se renovó el Consejo General de esa institución). El consenso partidista supone que al menos los tres partidos más importantes validan y dan un voto de confianza a los miembros del Consejo General del IFE (por participar entre todos la designación de esos funcionarios). En 2003, al renovarse una vez más el Consejo General, el PRD quedó fuera del proceso, lo que dio un grave golpe a la credibilidad futura del instituto que, junto con el Tribunal Electoral del Poder Judicial de la Federación (TEPJF), han sido puntales de la democratización mexicana. La izquierda perredista se sintió injustamente marginada en ese procedimiento (tanto el PRI como el PAN pudieron haberlo evitado), y negó dar un voto de confianza al nuevo IFE, lo que le facilitaría eventualmente cuestionar la imparcialidad del mismo, pues además resultó que los grupos que directamente designaron a los consejeros electorales fueron Elba Esther Gordillo por parte del PRI, y el equipo de Felipe Calderón, por parte del PAN. Es decir, justo la alianza informal pero operativa que ganó la elección en 2006 por un escaso margen. A partir de entonces, el proceso de radicalización del PRD empezó a resurgir.

Poco más adelante, surgieron varios videos que mostraban movimientos de corrupción de algunos funcionarios del gobierno capitalino, lo que implicaba un fuerte golpe político a López Obrador. El problema consistió en que el manejo y divulgación de tales videos tuvo como eje al gobierno federal, en combinación con personajes como el senador panista Diego Fernández de Cevallos y el ex presidente Carlos 
Salinas de Gortari. Que estos personajes se encargaran de la estrategia mediática contra López Obrador no sería nada anormal en una democracia (por el contrario, en la democracia las pugnas políticas pueden contribuir a la rendición de cuentas). En cambio, la injerencia en ello del poder ejecutivo implica el uso del Estado, su aparato y recursos, para incidir sobre la contienda político-electoral, lo cual rompe con las reglas básicas del juego democrático (pues contra los recursos del Estado es imposible competir, como ocurría bajo el régimen priísta que por eso mismo no podía ser considerado democrático). En otras palabras, el nuevo gobierno emanado del PAN empezaba a incurrir en algunas de las prácticas que desde la oposición condenó, como no respetar los principios básicos de la democracia electoral. Eso fue tomado por la izquierda como la ruptura del acuerdo democrático que se acordó bajo el gobierno de Zedillo y que fue respetado en lo esencial por éste (y por eso se rehusó a utilizar los recursos del Estado para forzar una vez más un triunfo presidencial del PRI en 2000).

El asunto del llamado 'video-escándalo' del gobierno capitalino restó algunos puntos a López Obrador en las encuestas de intención política, que encabezaba desde meses atrás, pero no al grado de conjurar el riesgo de que ganara la elección presidencial. Entonces el gobierno federal aprovechó una falta menor del gobierno federal para emprender un nuevo embate político. El gobierno capitalino había desacatado una orden judicial al no despejar la maquinaria utilizada para hacer un camino en una propiedad privada, que comunicaría un hospital sin accesos adecuados. El camino no se hizo pero la orden de remover la maquinaria tardó algunas semanas, por lo cual el gobierno decidió solicitar al Congreso el desafuero del jefe del gobierno capitalino para poder aplicar la ley. El gobierno de Fox manejó esta maniobra como un esfuerzo por fortalecer el estado de Derecho, si bien había dejado impunes graves actos de corrupción de miembros del PRI, como el desvío de fondos petroleros a la campaña presidencial del 2000 por parte de los líderes del sindicato de Pemex, miembros del Congreso, lo que exigía también procesos de desafuero que los legisladores del PRI y el PAN acordaron congelar para no afectar a dichos líderes. 
El PRD adujo, en cambio, que se trataba de una jugada política para inhabilitar políticamente a López Obrador, puntero indiscutible en las preferencias electorales. Y es que ese tipo de desacatos podían simplemente desecharse (como había ocurrido en múltiples casos), o bien buscar su penalización legal, lo que implicaba primero desaforar al jefe capitalino, cosa que Fox solicitó hacer a la Cámara de Diputados. Los diputados del PAN y el PRI acordaron desaforar a López Obrador, pese a haber acordado no hacer lo mismo con los corruptos líderes sindicales, cuya falta involucraba cerca de 1,500 millones de pesos.

La opinión pública, en su mayoría (hasta el $80 \%$ de acuerdo a varias encuestas), se inclinó por ver el proceso de desafuero más bajo la óptica del PRD (una maquinación política para sacar a López Obrador de la contienda presidencial) que bajo la versión del gobierno federal (la estricta aplicación de la ley aún ante una falta administrativa menor). La prensa internacional, igualmente, presentó el caso no como un proceso legal, sino como una jugarreta política de Fox para deshacerse de López Obrador. Eso, y una intensa movilización de diversos grupos ciudadanos (que incluyó una mega-marcha de más de un millón de asistentes en el centro de la capital), orillaron a Fox a desistir de su estrategia, dando marcha atrás por medio de una opción jurídica cuya viabilidad meses atrás había negado (con lo cual confirmó en los hechos que, en efecto, el desafuero no era la única alternativa legal, sino que tenía intencionalidad política). ${ }^{18}$

De ese episodio salió vencedor López Obrador, no sólo porque Fox dio marcha atrás en el desafuero, sino porque la popularidad e intención de voto del candidato perredista se elevó, en lugar de disminuir. La estrategia del desafuero fue burdamente diseñada y operada, por lo cual resultó contraproducente a sus objetivos esperados. Peor aún, la izquierda lo interpretó como una nueva muestra de que había una clara intención del gobierno federal de detener el avance de López Obrador, echando mano de los recursos estatales (en este caso la Procuraduría

${ }^{18}$ Cfr. Jorge Castañeda y Rubén Aguilar, La diferencia: radiografía de un sexenio, 2007, México, Grijalbo. 
General de la República), un desconocimiento de Fox del acuerdo democrático forjado durante el sexenio anterior. Jorge Castañeda, ex canciller del gobierno de Fox, había declarado que, en efecto, se trataba de detener a López Obrador "por las buenas, por las malas o como fuera", es decir, por medios lícitos o no, democráticos o no. El mensaje al PRD y a otros segmentos de la izquierda identificados con López Obrador fue que había la determinación de impedir su eventual llegada a la presidencia, pasando por alto las reglas elementales de la democracia. Con ello, se empezó a dar la polarización social y política, y la radicalización de la izquierda, pues sentía -no sin fundamento-que los canales institucionales se le obstruían una vez más (como en el gobierno de Salinas de Gortari). Pese a que el candidato del PRD seguía gozando de gran ventaja en las encuestas electorales, la izquierda sabía que enfrentaría una fuerte resistencia por parte del gobierno federal y otros actores políticos cuyos intereses podrían ser afectados ante una eventual llegada de López Obrador a la presidencia. Bajo ese clima político, polarizado, enrarecido, rijoso, escaso en confianza electoral, y con una izquierda crecientemente radicalizada, se llegó al proceso electoral (que formalmente inició en octubre de 2005). La política de Fox hacia la oposición fue pues muy similar a la seguida por Salinas de Gortari (hostigar y bloquear al PRD), que terminó su gobierno con una crisis política, en lugar de seguir la estrategia de Zedillo (abrir el juego político a todas las oposiciones y dejar a la ciudadanía tomar la elección final en las urnas), que terminó su sexenio en medio de civilidad, consenso y estabilidad. Por lo cual, desde entonces, se podían vislumbrar nubarrones en el horizonte de fin del sexenio.

\section{La injerencia electoral de Fox}

En efecto, Fox no cejó, tras el torpe ardid del 'desafuero', en su intento por detener "por las buenas, las malas o como fuera" (Castañeda dixit) el eventual triunfo de López Obrador, que inició la campaña electoral con aproximadamente 10 puntos de ventaja sobre sus contendientes: 
Felipe Calderón del PAN, y Roberto Madrazo del PRI. Calderón había ganado en buena lid la elección interna del PAN frente al favorito de Fox, el secretario de Gobernación, Santiago Creel. Madrazo recurrió a todo tipo de artilugio para imponerse como candidato, lo que provocó divisiones y rupturas en el partido, además de arrojar una mala imagen que se tradujo en la rápida caída de su candidato al tercer lugar en las encuestas, lo que provocó el fenómeno de 'voto útil', es decir, que muchos de quienes ven a su favorito sin posibilidades reales, sufragan por quien consideran como el 'mal menor' entre los dos punteros. Muchos de quienes veían a López Obrador como el candidato a vencer (con quien fuera), transfirieron su apoyo de Madrazo a Calderón, quien todavía hacia marzo estaba cerca de 10 puntos porcentuales por debajo del abanderado perredista.

El presidente Fox decidió entrar de lleno en la campaña electoral para apoyar al candidato de su partido. Así lo había hecho ya en los comicios intermedios del 2003, generando malestar entre la oposición, hasta que fue orillado, por la presión de la opinión pública y del propio IFE, a salir de la contienda. ${ }^{19} \mathrm{Y}$ en la elección presidencial, Fox decidió nuevamente intervenir con declaraciones y discursos (aunque de manera indirecta) para respaldar al Calderón y descalificar a López Obrador. El tema es, desde luego, sumamente polémico en México, pues se alega que en las democracias consolidadas, los presidentes en vigor tienen todo el derecho para respaldar públicamente al candidato de su partido (que a veces son ellos mismos, cuando buscan reelegirse) sin que ello implique una falta a la democracia. Lo que las reglas de la democracia no permiten es, como se dijo antes, el uso directo de los recursos económicos, humanos, logísticos o administrativos del Estado para favorecer a un candidato. De hecho, esto está tipificado en México como un delito electoral (más allá de que la Fiscalía Especial en realidad no haya servido de mucho para penalizar tales ilícitos). En efecto, en México tampoco estaba prohibido legalmente que los gobernantes (de distintos niveles), incluido el presidente, se pronun-

${ }^{19}$ Cfr. Lajous, Vicente Fox: el presidente..., op. cit., p. 155-64. 
ciaran por el candidato de su preferencia. El problema no era tanto de índole legal, sino histórico-cultural. Y es que, tras 70 años de haber vivido en un sistema de partido hegemónico (el PRI), una de cuyos rasgos fue justamente la ilícita utilización de los recursos del Estado para favorecer a los candidatos oficiales, la sensibilidad de la oposición al respecto era grande y comprensible. Cualquier intervención del Ejecutivo en la contienda, incluso declarativa, tiende a verse como una reproducción de las prácticas hegemónicas, todavía frescas en la memoria ciudadana.

El propio Fox, durante la campaña de 2000, exigía al presidente Zedillo 'sacar las manos' de la elección, incluso declarativamente, por esa misma hipersensibilidad de la oposición, generada por décadas de una franca injerencia del gobierno en los comicios. Zedillo sí aceptó quedar al margen del debate electoral, lo que facilitó el triunfo de Fox, por lo que se hubiera esperado que el presidente panista hiciera lo propio en 2006, en cuyo caso tal decisión se hubiera convertido en una nueva 'regla no escrita', sin necesidad de que fuese plasmada en la ley. Pero Fox incurrió justo en aquello que criticó en sus tiempos de opositor. De hecho, cuando el TEPJF evaluó la elección en lo que toca a la intervención de Fox en la campaña (que el PRD denunció como una irregularidad que vulneraba la equidad de la elección), los magistrados la consideraron como algo indebido, sobre la base, establecida por jurisprudencia, de que el peso de un gobernante no es el mismo que el de un ciudadano que libremente se expresa a favor o en contra de los candidatos. En efecto, al anular los comicios a gobernador en Colima (2003), el Tribunal había sentenciado que:

Se reconoce la alta investidura jurídica del gobernador del Estado, su importancia social y política. De ahí la razón por la cual se debe controlar su conducta (pues) a diferencia de lo que ocurre con las irregularidades cometidas por otros ciudadanos [...] las realizadas por el gobernador del Estado, en principio, deben considerarse graves [...] La equidad en las oportunidades en materia de comunicación y difusión para los partidos políticos constituye, entre otros, un elemento esencial para una elección democrática, la cual no puede preservarse cuando un servidor 
público del máximo nivel ejecutivo se pronuncia a favor de determinado candidato y/o en detrimento de los contendientes, de manera incesante, frecuente, deliberada y a través de los medios oficiales o informales o bien, institucionales o no, que en razón de su cargo o investidura, tiene a su alcance. ${ }^{20}$

Es precisamente lo que hizo Fox en 2006, y por lo que en el dictamen final sobre ella, el Tribunal señaló como ilícita la intervención del presidente, al grado de que 'pudo haber invalidado' la elección. Si decidió no hacerlo, fue porque no consideró que dicha intervención hubiera sido determinante en el resultado. ${ }^{21}$ En cambio, el propio Fox consideró que su participación sí fue determinante, a partir de diversas encuestas que midieron el impacto de su participación. De acuerdo con Rubén Aguilar (quien fue vocero de Fox) y Jorge Castañeda (su primer canciller): "Los encuestadores que disponen de levantamientos durante la jornada en su totalidad [...] coinciden en su conclusión: Fox benefició a Calderón, sin la menor duda y en vista del estrechísimo margen de victoria del candidato del PAN, es posible que sin Fox no hubiera ganado." 22

En todo caso, de nuevo el efecto político de tal intervención fue considerada por el PRD y sus aliados como reflejo de la decisión previamente tomada por Fox para detener el avance de López Obrador, con medidas que desde su óptica alteraban las reglas de la contienda democrática. Algo que de alguna forma fue ratificado después por el propio Fox:

Yo tuve mi propio problema con el Alcalde de la Ciudad de México, Andrés Manuel López Obrador. Tenía un dilema de, por un lado, cumplir la ley y respetar la orden del juez o, por el otro lado, el reclamo de López

${ }^{20}$ TEPJF, Expedientes, Sup-Jrc/221-2003.

${ }^{21}$ Dictamen relativo al cómputo final de la elección de presidente de los Estados Unidos Mexicanos, declaración de validez de la elección y de presidente electo, 5 de septiembre de 2006.

${ }^{22}$ Castañeda y Aguilar, La diferencia..., op. cit., p. 368. 
Obrador de que su candidatura a la Presidencia se respetara. Fue una decisión difícil. Y perdí. Entonces me retiré. Pagué el costo político, pero 18 meses más tarde me desquité cuando ganó mi candidato. ${ }^{23}$

Luego entonces, la intervención de Fox en la campaña, que sí consideró determinante en su resultado, fue continuación del fallido esfuerzo desplegado durante el episodio del 'desafuero'.

\section{Los errores de López Obrador}

De cualquier manera, debe decirse que la intervención de Fox -lícita o no- no hubiera impedido el triunfo de López Obrador, dada la enorme ventaja que todavía en marzo registraba en las encuestas (cerca del $10 \%$ ), de no haber cometido graves errores que le mermaron esa ventaja de manera dramática. López Obrador descuidó una regla fundamental en los comicios democráticos: el llamado 'voto duro', formado por los partidarios incondicionales (o casi), gustan de un discurso radical y extremista. Pero si con ese segmento no es posible ganar una elección -como frecuentemente no lo es- entonces se requiere contar con el voto de otros sectores más moderados, que se distinguen en que su respaldo no es incondicional, que no gustan de las expresiones radicales ni de la estridencia discursiva, y que no tienen mayor problema en cambiar de preferencia o simplemente alejarse de las urnas. La mayor parte de las preferencias de López Obrador estaba formada por votantes moderados.

El radicalismo en el discurso del candidato del PRD, que incluía una descalificación indiscriminada a los grupos empresariales, y que culminó con descalificativos estridentes hacia el presidente Fox, abrió un hueco que le permitió a sus rivales (en particular al PAN) presentarlo creíblemente como "un peligro para México" (según rezaba una de las consignas de la publicidad panista). En otras palabras, por darles gusto

${ }^{23}$ El Universal, 13 de febrero de 2007. 
en la plaza a sus votantes duros (una minoría que de cualquier forma no iba a perder) descuidó a sus partidarios moderados, sin los cuales no podía ganar y que fácilmente podían cambiar su preferencia, como muchos hicieron durante los meses y semanas previos a la elección. Pero no fue el único error. También lo fue haber decidido no asistir al primero de dos debates presidenciales, por un error de cálculo. Suele ocurrir que el candidato que lleva la ventaja arriesga en un debate, y son sus rivales los que más tienen que ganar en esos encuentros. Al plantearse el primer debate, López Obrador se hallaba aún muy por encima de sus seguidores, por lo cual decidió no asistir y reservarse para el segundo debate simplemente. Además, en el momento en que se celebró ese primer debate, era ya un hecho el descenso del candidato perredista en las encuestas. ${ }^{24}$

Finalmente, debe señalarse también como un error haber decidido no aparecer en los medios, por una medida de austeridad que hipotéticamente el ciudadano recompensaría en las urnas. En principio quizá sí, pero cuando se es objeto de una fuerte y eficaz campaña negativa, conviene más responderla puntual y oportunamente y no dejar que lo dicho por el adversario quede como una verdad no desmentida ('el 94 que calla, otorga'). Los medios electrónicos alcanzan un vasto público, en tanto que la campaña territorial, en la que se va de plaza en plaza, sólo llega a pocos ciudadanos que, además, son aquéllos con cuyo voto ya se cuenta (el votante duro). Así pues, López Obrador repitió algunos de los errores cometidos por Cuauhtémoc Cárdenas durante la campaña de 1994, de cuyos trompicones no fue capaz de extraer las lecciones pertinentes para no tropezar con las mismas piedras con que topó Cárdenas doce años atrás. ${ }^{25}$ Es cierto que, al final, el candidato perredista decidió utilizar la publicidad mediática con mayor fuerza, responder parte de las acusaciones y descalificaciones que se le hacían, e incluso incurrir también en 'campaña negativa' (que tiene lo mismo

${ }^{24}$ Cfr. Lajous, op. cit., p. 384-407.

${ }^{25}$ Adolfo Aguilar Zínzer, ;Vamos a ganar! La pugna de Cuauhtémoc Cárdenas por el poder, 1995, México, Océano, p. 142. 
aspectos positivos que negativos para el electorado). Pero todo indica que fue demasiado tarde. La curva de caída en las encuestas apenas se equilibraba cuando llegó el fin de la larga campaña. Los errores fueron ya irreparables (Gráfica 2).

\section{GRÁFICA 2}

PREFERENCIAS ELECTORALES - 2006

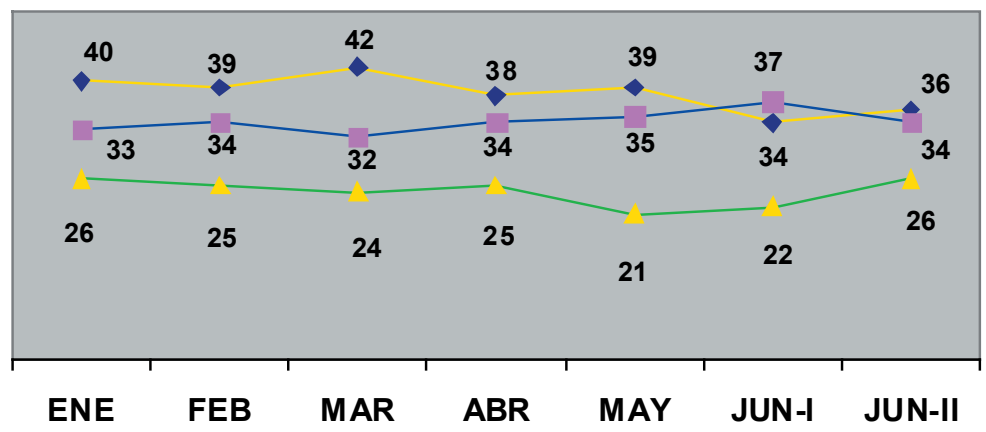

\section{AMLO - - CALDERON - -MADRAZO}

FUENTE: El Universal, 23 de junio 2006.

Tales equivocaciones minaron gravemente las preferencias electorales de López Obrador, al grado de que en las últimas encuestas previas a los comicios, la mayoría reflejaba un 'empate técnico' con Calderón, lo que supone que cualquiera de estos dos contendientes podía ganar, y seguramente lo haría por un margen estrecho. De modo que los errores de campaña de López Obrador pueden explicar en buena parte que haya perdido la ventaja que garantizaba su triunfo, si bien no basta para explicar su derrota oficial, dado el estrecho margen entre el primero y segundo lugar, según se explicará en seguida. 


\section{Una elección reñida}

Puede decirse que la elección presidencial del 2006 representó un fracaso en tanto que no pudo generar consenso sobre el resultado, o la convicción generalizada de que quien ganó oficialmente, Felipe Calderón, lo hizo en buena lid. Las elecciones democráticas diseñan sus reglas y condiciones para elevar la probabilidad de que dicho consenso se dé, pues en esa medida es más factible que la pugna por el poder se dirima de manera pacífica y civilizada, se proteja la estabilidad política, se fortalezcan las instituciones públicas y las autoridades emanadas del proceso gocen de suficiente legitimidad. Al no haber consenso electoral, todo ello se logra en menor medida o, en el extremo, se llega a perder. Desde luego, una elección organizada democráticamente no garantiza que se alcance dicho consenso, simplemente eleva significativamente la probabilidad de que ello ocurra. Pero toda institución humana es falible y también lo son las elecciones, pese a contar con un formato democrático. Por eso mismo, países con gran tradición y solidez democrática pueden también experimentar dudas e impugnaciones sobre los resultados oficiales, como ocurrió en Estados Unidos en el año 2000, o en Alemania e Italia en 2005 y 2006.

La mayor equidad en la contienda, la imparcialidad de las autoridades que organizan y califican los comicios, así como la pulcritud del proceso electoral, son elementos que contribuyen a obtener el consenso electoral (y por ende, la aceptación del veredicto por parte de los perdedores). Pero no siempre es posible garantizar tales condiciones, o mejor dicho, casi nunca lo es. Siempre quedará algún remanente en cuanto a la equidad, imparcialidad o pulcritud; los partidos gobernantes suelen gozar de alguna ventaja por el solo hecho de serlo. Tampoco es posible evitar por completo que los contendientes intenten incidir sobre la votación incurriendo en conductas ilícitas, cuando no ilegales. No puede presumirse una perfecta organización, limpia de anomalías, sean éstas resultado de errores humanos, el diseño de la boleta o la forma de ser llenada, fallas en el conteo, o bien producto de acciones 
dolosas, aisladas u orquestadas. Y aun en caso de que no hubiera mala fe, los errores y anomalías pueden opacar la claridad del resultado de ser éste sumamente cerrado, como lo fue en la elección presidencial del 2006 (233,831 votos de ventaja para el ganador, es decir, $0.56 \%$ de la votación total).

De lo que se trata en una democracia electoral es, entre otras cosas, de reducir las condiciones para que no ocurra todo lo anterior, con el propósito de que inevitables anomalías o inequidades no se vuelvan determinantes en el resultado final. Cosa que, sin embargo, se dificulta si la distancia entre el ganador oficial y su más cercano seguidor es muy reducida, pues en tal caso ese pequeño número de irregularidades -así sean meros errores humanos- podría nublar la certeza en el veredicto final. En otras palabras, si bien es verdad que una regla de la democracia electoral es que "por un voto se gana o se pierde" (lo cual es cierto dependiendo del sistema electoral en cuestión), un corolario lógico es que, en tal circunstancia, "basta un voto dudoso o irregular para no sea posible determinar con certeza quién ganó".

Es decir, mientras más cerrado es un resultado, más limpia y equitativa debe ser la elección para que un veredicto estrecho genere, pese a todo, consenso y credibilidad entre los participantes y sus respectivos partidarios. De lo contrario, surgirán la incertidumbre, la duda, la impugnación, el cuestionamiento sobre la credibilidad en la elección misma y la legitimidad de su ganador oficial. Y por eso, una reducida ventaja para quien obtiene el primer sitio puede hacer que las inequidades, errores, inconsistencias, incluso si son de una magnitud relativamente pequeña, puedan afectar la claridad del resultado al grado de no saber con certeza quién fue el ganador de la contienda. Fue justamente un resultado cerrado en las elecciones a gobernador de Tabasco en 2000, y de Colima en 2003, lo que llevó al (TEPJF) a considerar como determinantes algunas inequidades y anomalías registradas durante el proceso electoral, aunque éstas no fueran monumentales. Así, en la sentencia correspondiente a la elección de Tabasco se lee, en relación con las anomalías e inequidades registradas: 
Esta afectación es decisiva en una elección cuyos resultados son muy cerrados. Esta escasa diferencia en la votación evidencia la importancia de las irregularidades de la elección [...] porque el surgimiento de cualquiera de ellas (las anomalías) pudo ser la causa de que un determinado partido fuera el triunfador, puesto que si las anomalías no se hubieran producido, el resultado podría haber sido otro. ${ }^{26}$

Bajo un resultado estrecho, las impugnaciones y denuncias sobre irregularidades hechas por quien resulta perdedor, tienen mayor probabilidad de ser creídas por sus seguidores e incluso ciudadanos que no sufragaron por ese candidato, precisamente porque no se requiere que tales irregularidades hayan sido monumentales para ser potencialmente determinantes en el resultado final. Cuando hay un amplio margen entre el ganador y el perdedor, y las irregularidades detectadas no bastan para explicar ese resultado, habrá poca verosimilitud en el reclamo de fraude y los propios seguidores del quejoso tenderán a dejarlo solo. De modo que, si en una elección reñida se detecta un cierto número de inconsistencias, una injerencia indebida del gobierno en vigor, alguna conducta o decisión parcial de la autoridad electoral a favor de quien a la postre resulte ganador, y a todo ello se le agrega un margen de victoria reducido, entonces el terreno para la suspicacia y la duda estará perfectamente abonado. Por ejemplo, el investigador Fernando Pliego aduce una serie de condiciones pre-electorales que afectaron la inequidad y la imparcialidad en cierto grado, para explicar por qué tanta gente aceptó como válida la tesis del fraude electoral esgrimida por Andrés Manuel López Obrador en el año 2006, muchas veces con argumentos no demostrados y poco verosímiles en sí mismos, pero creíbles en su conjunto (aunque no llegaran a ser ciertos). ${ }^{27}$

Los efectos nocivos de un resultado estrecho dependen también del sistema político y electoral en cuestión, pues en algunos casos (suele ser típico de los regímenes parlamentarios), el gobierno nacional no depende exclusiva ni determinantemente del número de votos

${ }^{26}$ TEPJF, Expedientes, Sup-Jrc/487-2000.

${ }^{27}$ Fernando Pliego, El mito del fraude electoral en México, 2007, México, Pax, cap. V. 
que obtenga cada partido en las urnas, sino del número de distritos de mayoría ganados (como en Inglaterra), o de las coaliciones que se formen después de la elección (como en los sistemas multipartidistas). Y por otro lado, mientras más joven es la democracia, mayor será la tentación de los perdedores a cuestionar el proceso electoral, y de sus seguidores a dar credibilidad a tales quejas (sobre todo con un resultado cerrado). ${ }^{28}$ En México, lo apretado del resultado en 2006 generó una situación parecida a la de Estados Unidos en el 2000. Tal y como Fox lo recuerda:

[En 2000] Hubo algo irónico; a petición nuestra, Estados Unidos había enviado observadores para proteger el proceso electoral en México, pero donde habrían sido más útiles, ese año, fue en Florida [...] Mientras observábamos por la CNN pasar 36 días de suspenso en Florida, con los jueces dictaminando las boletas en busca de falsificaciones; nunca soñamos que mi propia presidencia terminaría con una competencia similarmente reñida en $2006 .{ }^{29}$

Sin embargo, en virtud de una institucionalidad democrática más incipiente y frágil que la norteamericana, la inconformidad no se asumió tan fácilmente, y si bien no se desató la violencia (en parte porque la institucionalidad heredada del PRI tampoco había desaparecido del todo), se rompió el consenso electoral que se había logrado seis años atrás. En cambio, se generó una fuerte polarización en la ciudadanía, cuyos efectos persisten en el ambiente político. En una elección sumamente cerrada, para que el veredicto final quede libre de toda duda - al menos a los ojos de la mayoría ciudadana-debe ser impecable, impoluta de toda irregularidad, inequidad o errores de escrutinio y cómputo, lo cual no ocurre ni en las democracias más desarrolladas. De hecho, tampoco fue muy distinto el nivel de anoma-

${ }^{28}$ Cfr. Christopher Anderson, André Blais, Shaun Bowler, Todd Donovan y Ola Listhaug, Losers 'Consent: Elections and Democratic Legitimacy, 2005, Nueva York, Oxford University Press.

${ }^{29}$ Vicente Fox y Rob Allyn, La revolución de la esperanza, 2007, México, Aguilar, p. 274. 
lías en la elección del 2000, considerada como la más democrática de la historia de México. La magnitud de errores de captación fue de $1.26 \%$ de votos por casilla en 2000 , y $1.35 \%$ en $2006 .{ }^{30}$ La diferencia consistió pues, en el margen de victoria: de casi $6 \%$ en 2000 y de $0.6 \%$ en 2006. Esas inconsistencias y errores, tanto en el 2000 como en el 2006, no parecen haber sido producto de un magno operativo para torcer la voluntad ciudadana, o al menos no se puede concluir tal a partir de la distribución de esas anomalías. ${ }^{31}$ Como quiera, dolosas o no, tales inconsistencias fueron suficientes en 2006 (a diferencia de lo ocurrido seis años antes) para arrojar dudas razonables sobre quién ganó en realidad.

Precisamente por ello, las autoridades electorales pudieron y debieron haber puesto todo su empeño en hacer el proceso de escrutinio y cómputo de los votos lo más transparente y exhaustivo posible -se registraron múltiples inconsistencias, fuesen o no dolosas. Mientras más transparencia tuvieran esos procesos, un mayor número de ciudadanos, independientemente de su preferencia electoral, hubieran dado por válido el resultado. ¿Pudieron el Instituto Federal Electoral (IFE), y el Tribunal Electoral del Poder Judicial de la Federación (TEPJF)

100 hacer un mayor esfuerzo por transparentar el proceso de escrutinio y cómputo de la votación? Sin duda.

\section{EI desempeño del IFE y del TEPJF}

Para recibir la votación de la ciudadanía, contarla y registrarla en las actas oficiales, el IFE se encarga de calcular e instalar un número suficiente de centros de votación con sus respectivas casillas. Pero en esa etapa se pueden cometer numerosos errores de captación al llenar las actas, arrojando múltiples inconsistencias aritméticas (donde las

${ }^{30}$ Cfr. Javier Aparicio, "La evidencia de una elección confiable", en Nexos, $\mathrm{n}^{\circ}$ 346, octubre 2006, p. 49-53.

${ }^{31}$ Cfr. Fernando Pliego, op. cit., cap. V. 
cifras de los distintos rubros captados no cuadran). E1 Programa Electoral de Resultados Preliminares (PREP) del IFE, registró un número de inconsistencias aritméticas superiores a los dos millones y medio (que superan en diez veces la diferencia con que ganó Calderón a López Obrador). Desde luego, muchas de esas inconsistencias, producto de errores humanos de captación, podían ser depuradas. Por eso mismo está previsto en la ley electoral que el IFE realice una segunda revisión de las actas y lleve a cabo el cómputo oficial de la elección por parte de un Consejo Distrital (uno por cada distrito electoral, que son 300). Estos Consejos tienen como responsabilidad -entre otras- realizar el cómputo de la elección por medio de las actas correspondientes a su distrito, y en los casos que prevé la ley, están facultados para abrir los paquetes electorales y proceder al recuento de las boletas ahí contenidas. El número de actas con inconsistencias aritméticas fue de aproximadamente 83 mil, es decir, el 65\% del total (un promedio de 275 actas por cada uno de los 300 distritos legislativos). El IFE decidió abrir y recontar sólo 2,873 paquetes, es decir, apenas un 3.5\% del total de paquetes cuyas actas registraban inconsistencias (un promedio de 9 paquetes por distrito). En muchos distritos, el número de actas abiertas fue sumamente reducido, incluso nulo, como se percibe en el Cuadro 1.

\section{Cuadro 1}

\section{NÚMERO DE DISTRITOS DONDE SE ABRIERON Y RECONTARON TRES O MENOS PAQUETES ELECTORALES}

$\begin{array}{lcccccccc}\text { Paquetes abiertos } & 0 & 1 & 2 & 3 & 4 & 5 & 6 & \text { Total } \\ \text { Número de distritos } & 22 & 29 & 32 & 24 & 24 & 24 & 24 & 155\end{array}$

En 107 de los 300 distritos (es decir, poco más de una tercera parte) se abrieron y recontaron 3 o menos paquetes, y en 155 de los distritos (más de la mitad) se recontaron 6 paquetes o menos, frente a un promedio de 275 actas inconsistentes por distrito (esto es, en más 
de la mitad de distritos se abrió 1 de cada 45 paquetes cuyas actas registraban inconsistencias aritméticas). Eso mismo generó acusaciones de parcialidad del IFE por parte del PRD, pues la estrategia seguida por el PAN era abrir el menor número posible de paquetes electorales. El IFE no debía de abrir ni más ni menos paquetes que aquellos que ordenaba la ley, pero abrió sólo el 3.5\% de los que, según la ley, debió haber recontado, y dejó sin revisar un elevado número de paquetes cuyas actas registraban errores aritméticos nada pequeños como puede apreciarse en el Cuadro 2):

\section{CuAdro 2}

MUESTRA DE ACTAS QUE REGISTRAN FUERTES ANOMALÍAS Y
NO FUERON ABIERTAS POR LOS CONSEJOS DISTRITALES DEL IFE.

\begin{tabular}{|c|c|c|}
\hline DISTRITO & CASILLA $^{*}$ & ERRORES ARITMÉTICOS \\
\hline OAX-3 & $1785 \mathrm{C} 7$ & 124 \\
\hline GTO-1 & $2902 \mathrm{C} 1$ & 157 \\
\hline DF-23 & $386 \mathrm{~B}$ & 180 \\
\hline MEX-1 & $4009 \mathrm{C} 1$ & 206 \\
\hline DF-15 & $4460 \mathrm{~B}$ & 231 \\
\hline ZAC-1 & $1279 \mathrm{~B}$ & 338 \\
\hline CHIS-9 & $1603 \mathrm{C} 1$ & 395 \\
\hline CHIS-8 & $1548 \mathrm{~B}$ & 399 \\
\hline CHIS-10 & $1832 \mathrm{C} 1$ & 482 \\
\hline CHIS-7 & $110 \mathrm{~B}$ & 483 \\
\hline
\end{tabular}

* La (B) se refiere a una casilla básica y la (C) a alguna contigua.

Ante esta situación, y la consecuente inconformidad del PRD, ¿cuál fue la respuesta del Tribunal Electoral? Una primera sentencia sobre la elección presidencial fue emitida por el TEPJF el 5 de agosto de 2006, en la que aborda la forma y los criterios en que el IFE realizó el 
recuento oficial, el 5 de julio del mismo año. ${ }^{32}$ El Tribunal reprendió al IFE por haber dejado sin revisar tantos paquetes cuyas actas mostraban inconsistencias (cerca de 80 mil actas, es decir, 96\% de las que debían revisarse). Y eso tenía que hacerlo de oficio, es decir, que para hacer dicha apertura "no se requiere petición de los partidos políticos". El Tribunal reclamó la falta de exhaustividad al IFE, obligación que, según una tesis relevante del propio Tribunal, consiste "en que las autoridades (electorales) agoten la materia de todas las cuestiones sometidas a su conocimiento, mediante el examen y determinación de la totalidad de las cuestiones concernientes a los asuntos de que se ocupen, a efecto de que no se den soluciones incompletas". ${ }^{33} \mathrm{Y}$ es que ello implicaba que el IFE descuidaba el "máximo beneficio posible, que se pudiera alcanzar en el procedimiento de depuración del recuento de la votación". ${ }^{34}$

Llegado a este punto, el TEPJF pudo haber instruido al IFE la reposición del procedimiento, para lo cual tiene plenas facultades legales. $\mathrm{O}$ bien pudo él mismo ordenar la revisión de las actas inconsistentes que no fueron revisadas por el IFE, para lo cual también tiene atribuciones, de acuerdo a una tesis de jurisprudencia en la que se lee:

A efecto de alcanzar el objetivo de certeza, rector del sistema de justicia electoral, se prevé como una atribución del órgano jurisdiccional electoral federal la de ordenar, en casos extraordinarios, la realización de alguna diligencia judicial, como sería la apertura de los paquetes electorales [...] (aunque ello) constituye una medida última, excepcional y extraordinaria que únicamente tiene verificativo cuando, a juicio del órgano jurisdiccional, la gravedad de la cuestión controvertida así lo exige, su eventual desahogo pudiera ser de trascendencia para el sentido del fallo -como ocurriese si pudiese ser determinante para el sentido de la

32 TEPJF, Expediente, Sup-Jin/212-2006 y otros, op. cit., agosto 5 de 2006.

33 "Exhaustividad, modo de cumplir este principio cuando se consideren insatisfechas formalidades esenciales", en Compilación Oficial de Jurisprudencia y Tesis Relevantes 19972005, 2005, México, TEPJF, p. 566-7.

${ }^{34}$ TEPJF, Sup-Jin/212-2006 y otros, op. cit., agosto 5 de 2006. 
elección-y (cuando) sólo se pueda alcanzar certidumbre a través de tal diligencia. ${ }^{35}$

Pero en lugar de ordenar la depuración de inconsistencias requerido para imprimir certeza en el resultado, el Tribunal ordenó abrir sólo una proporción reducida de los paquetes que quedaban aún sin revisar: 11,718 casillas, que corresponde al 15\% de las actas inconsistentes. En total, entre el IFE y el Tribunal se recontaron 14,594 los paquetes electorales abiertos, aproximadamente el 18\% de las más de 83 mil actas que registraban errores aritméticos de manera evidente, y que el Cofipe estipula debían ser recontadas de oficio, de acuerdo a la interpretación que hizo el propio Tribunal. Eso, pese a que los observadores electorales de la Unión Europea recomendaban el recuento total para disipar toda duda, y en ese mismo sentido se manifestaba buena parte de la prensa extranjera. El Financial Times, por ejemplo, escribió en una editorial que convenía realizar el recuento total, pues "resolvería de una vez por todas quién ganó la elección y se enviaría un mensaje claro de que México es una democracia transparente. Si un recuento confirma su triunfo, eso ayudará a Calderón a gobernar más efectivamente". ${ }^{36}$ Según algunas encuestas, alrededor de un $72 \%$ de los ciudadanos veía bien la revisión de todas las casillas para imprimir mayor certeza al resultado de la elección. ${ }^{37}$

La decisión del Tribunal de revisar sólo una pequeña proporción de paquetes electorales fue también tomada por el PRD como una señal de parcialidad de los magistrados electorales, pues coincidía con la estrategia del PAN. El propio equipo de Felipe Calderón, y él mismo, posteriormente reconocieron que lo que más les convenía era abrir el menor número de paquetes electorales posible, pues en realidad no

35 "Paquetes electorales. Sólo en casos extraordinarios se justifica su apertura ante el órgano jurisdiccional", en Compilación Oficial de Jurisprudencia y Tesis Relevantes 19972005, 2005, México, TEPJF, p. 211 (cursivas mías).

${ }^{36}$ Cfr. Alejandra Lajous, Confrontación de agravios: La postelección de 2006, 2007, México, Océano, p. 44.

${ }^{37}$ Cfr. Excélsior-Parametría, 28 de julio de 2006. 
sabían bien a bien qué contenían esos paquetes, por lo que su recuento amplio podía arrebatarles el triunfo que ya tenían en las manos. El propio Calderón narró que en un primer momento consideró que sería positivo el recuento para su causa, pues podría darle más credibilidad a un triunfo del cual él mismo no dudaba. El 10 de julio, es decir, días después del recuento oficial del IFE, cuenta: "Reuní a mi equipo y dije 'vamos al recuento. No tengo la menor duda'. Es más, probablemente un recuento hubiera dado más votos, porque si alguien hizo trampa fue el PRD en el DF [...] yo no tenía preocupación." 38 Sin embargo, miembros de su equipo lo convencieron de que un recuento podría implicar el riesgo de mayores anomalías que las detectadas hasta entonces. Uno de sus colaboradores explica:

La apertura total podría mostrar elementos o irregularidades, hasta entonces no probadas, que le dieran (al PRD) el sustento que necesitaba para pedir la nulidad de la elección. No habían podido sustentar ninguno de los distintos tipos de fraude que decían habían existido, ni ninguna cuestión para la nulidad. Lo único que podría darle argumentos al Tribunal de dónde agarrarse para anular la elección era precisamente la apertura, porque con ésta iba a haber errores, iba a haber inconsistencias, iba a haber incluso algunas casillas seguramente donde con dolo se hizo trampa, a favor de uno o de otro, donde no cuidaron los demás y alguien se pasó de listo. ${ }^{39}$

Calderón terminó convenciéndose de ese razonamiento: “efectivamente, si hubiéramos ido a un recuento en ese momento de desorden, lo que hubiera sacado el PRD es un argumento político para anular la elección". ${ }^{40}$ El Tribunal no debía, en efecto, respaldar en los hechos ni la estrategia del PAN ni la del PRD, sino hacer lo que la ley le facultaba para buscar la máxima certidumbre posible. Al quedar más del 80\% de

${ }^{38}$ Citado por Salvador Camarena y Jorge Zepeda Patterson, El presidente electo: Instructivo para sobrevivir a Calderón y su gobierno, 2007, México, Planeta, p. 187.

${ }^{39}$ Ibid., p. 186.

${ }^{40}$ Ibid., p. 187. 
actas inconsistentes sin revisar por ninguna autoridad, el PAN obtuvo un triunfo estratégico. Pero evidentemente eso dejó sin despejar la incógnita sobre cuántas inconsistencias aritméticas que no pudieran ser justificadas ni depuradas (votos irregulares) quedaron en las actas, y si su número sería tal que opacara la certeza del resultado. De acuerdo a la lógica que rige la normatividad electoral, si el número de votos irregulares no justificables igualara o superara la cantidad de sufragios con que el primer lugar aventaja al segundo, no sería posible saber cuál fue la voluntad del electorado. Precisamente, cuando esa situación prevalece en alguna casilla, ésta debe ser anulada, según la ley. Así, una tesis de jurisprudencia señala que:

No es suficiente la existencia de algún error en el cómputo de los votos, para anular la votación recibida en la casilla impugnada, sino que es indispensable que aquél sea grave, al grado de que sea determinante en el resultado que se obtenga, debiéndose comprobar por tanto, que la irregularidad revele una diferencia numérica igual o mayor en los votos obtenidos por los partidos que ocuparon el primero y segundo lugares en la votación respectiva. ${ }^{41}$

¿Qué sucedería si dicha situación se diera también a nivel nacional, es decir, que el número de votos irregulares, no justificados ni depurados, superase a los 233,831 sufragios con que Calderón aventajó oficialmente a López Obrador? Pues al igual que en las casillas anuladas por el Tribunal, se violentaría la certeza en el recuento de votos. No se podría saber, en otras palabras, cuál fue la voluntad del electorado ni, por tanto, quién fue el legítimo ganador. Equivaldría a declarar 'desierto' el primer lugar de la contienda (es decir, no podría validarse la elección ni nombrar presidente electo). Es decir, dada la falta de certeza, lo procedente hubiese sido anular la elección (como ocurrió en Tabasco en 2000, y en Colima en 2003).

41 "Error grave en el cómputo de votos. Cuándo es determinante para el resultado de la votación”, en Compilación Oficial de Jurisprudencia y Tesis Relevantes 1997-2005, 2005, México, TEPJF, p. 116. 
El Tribunal, en su dictamen final, señaló que el número de inconsistencias en su mayoría fue debidamente justificado y que las que no lo fueron no superaban la ventaja con la que oficialmente Calderón aventajó a su más cercano seguidor. Por lo cual, la certeza del resultado no estaba en duda. Sin embargo, al revisar las actas de 150 de los 300 distritos electorales, resulta que los votos irregulares plenamente justificados no constituyeron una mayoría y los restantes superan la diferencia que oficialmente se adjudicó a Felipe Calderón sobre Andrés López Obrador. Así, los votos irregulares contabilizados fueron 365,995 , pero de ellos 49,456 estuvieron plenamente justificados a partir de los criterios establecidos por el Tribunal Electoral, quedando entonces 316,539 votos irregulares sin justificar. Esos votos, irregulares en sí mismos, rebasan los 233,831 con que Calderón superó oficialmente a López Obrador. La proyección de esos votos irregulares a 300 distritos rebasan los 600 mil. ${ }^{42}$ Es decir, lo que prevalece según las actas oficiales de escrutinio y cómputo no es un triunfo claro e inequívoco de Felipe Calderón, tal como lo afirma el Tribunal Electoral en su dictamen final, sino la imposibilidad de saber con certeza cuál fue la voluntad del electorado. Lo jurídicamente procedente, en tal circunstancia, hubiera sido anular la elección y convocar a una extraordinaria (aunque ello supusiera ciertos riesgos políticos en un país donde desde 1920 la transferencia del poder no siempre fue democrática, pero sí puntual).

En todo caso, el Tribunal se apegó a la primera parte de la llamada 'regla de oro' de la democracia, según la cual "quien gana por un voto de diferencia, gana con plena legitimidad". Pero los magistrados del Tribunal hicieron caso omiso del corolario natural de ese principio: "si se gana por un solo voto, entonces basta un voto irregular o mal contado para que ya sea imposible saber con certeza por quién se inclinó la mayoría de los electores". Por eso era importante llevar a cabo un recuento mucho más amplio del que se hizo, al menos de

${ }^{42}$ Cfr. José Antonio Crespo, 2006: hablan las actas, 2008, México, Random House Mondadori, (en prensa). 
JOSÉ ANTONIO CRESPO

aquellos paquetes cuyas actas eran inconsistentes (el 63\% del total), para así imprimir certeza electoral al reducirse posiblemente los votos irregulares por debajo de la diferencia entre primero y segundo lugar. En tal caso, hubiera sido posible generar el mayor consenso en torno al resultado y mayor legitimidad para el ganador oficial. Pero, debido a que no fue así, podemos bautizar la del 2006 como la 'elección incierta'. 